\title{
Extraocular muscle surgery for Graves' ophthalmopathy: does prior treatment influence surgical outcome?
}

\author{
Maarten Ph Mourits, Leo Koorneef, Ada M van Mourik-Noordenbos, \\ Helma M van der Meulen-Schot, Mark F Prummel, Wilmar M Wiersinga, Arie Berghout
}

\begin{abstract}
We analysed the results of extraocular muscle surgery in 38 patients with stable Graves' ophthalmopathy. Fixed sutures were used in all patients. A useful field of binocular single vision was achieved in 27 patients $(71 \%)$ after one operation and in seven patients $(18 \%)$ after more than one, whereas double vision was persistent in four (11\%). No recurrence of diplopia was seen during one year of follow-up. No differences were found in duration of eye disease, angle of deviation, or in prior forms of treatment between patients who responded well to a single operation and those who needed more surgical procedures or those who responded less well. We conclude that, although the individual outcome cannot be predicted, every patient with diplopia and stable Graves' ophthalmopathy has an $89 \%$ chance of binocular single vision after extraocular muscle surgery. Prior treatment does not appear to influence this outcome.
\end{abstract}

Ocular motility imbalance resulting in diplopia or torticollis is frequently found in patients with Graves' ophthalmopathy. ${ }^{12}$ During the period of active inflammation treatment of the disease with steroids or radiotherapy is rational. ${ }^{34}$ After the inflammation has subsided and the disease has stabilised the remaining diplopia can be dealt with surgically. ${ }^{5}$ However, extraocular muscle surgery in patients with Graves' ophthalmopathy fails in at least $10 \%$ of cases. ${ }^{26}$

The aim of this study was to determine whether duration of eye disease, angle of deviation, or prior treatment (prednisone, cyclosporin, and especially orbital irradiation or orbital decompression) would influence the outcome of surgery.

University of Amsterdam, The Netherlands Orbital Centre

M Ph Mourits

L Koornneef

A M v Mourik-

Noordenbos

H M v d Meulen-Schot

Department of Endocrinology M F Prummel W M Wiersinga A Berghout

Correspondence to M Ph Mourits, Orbita Medisch Centrum A-2 116, Meibergdreef 9, $1105 \mathrm{AZ}$ Amsterdam, The Netherlands.

Accepted for publication 8 March 1990 From January 1987 to December 1988 we performed extraocular muscle surgery for diplopia on 38 patients with Graves' ophthalmopathy. Ten were male and 28 female. Their age at operation ranged from 29 to 84 , average $54 \cdot 5$ years. The diagnosis of Graves' ophthalmopathy was based on clinical findings and enlargement of the extraocular muscles on CT scan. All patients were classified in NOSPECS class 4 , grade b. Prior to extraocular surgery only four patients had never had any treatment for their Graves' ophthalmopathy. Nine patients had been treated with immunosuppressive treatment (including prednisone, maximum dose $60 \mathrm{mg} /$ day, and/or cyclosporin, $7.5 \mathrm{mg} / \mathrm{kg} /$ day); 12 patients with orbital irradiation, total dose $20 \mathrm{~Gy}$ (with or without medical treatment), and 13 patients had undergone orbital decompression (after or without medical and/or radiation treatment). Eleven of the 13 patients who underwent decompression already had diplopia before this operation. All patients were euthyroid at the time of surgery and had stable eye disease, defined as: unchanging proptosis, constant angle of deviation, and stable visual acuity for at least three months. All patients experienced diplopia, which could not be relieved by prisms. Eighteen patients (47\%) had hypotropia, 8 (21\%) had esotropia, and 12 $(32 \%)$ had both hypo- and esotropia. The range of esotropia was 8 to 45 dioptres and the range of hypotropia 4 to 22 dioptres.

A synopsis of the muscles operated on is given in Table $I$. In most cases a recession of the inferior or medial rectus muscle was performed. Fixed sutures were used in all patients. The amount of surgery was decided upon by the angle of deviation. For hypotropia the amount of inferior rectus recession varied from 2.5 to $5.0 \mathrm{~mm}$, average $3.3 \mathrm{~mm}$. Special care was taken to dissect the muscle free of all its attachments to the conjunctiva, the lower lid retractors, and the inferior oblique muscle. In one patient a complete tenotomy of the inferior and medial rectus muscle was performed. For esotropia the amount of medial rectus recession varied from 3.5 to $8.0 \mathrm{~mm}$ on both sides. Two surgeons ( $\mathrm{LK}$ and $\mathrm{MPhM}$ ) performed the operations.

The outcome of surgery was assessed three months after the operation. The field of binocular single vision was measured with the Maddox cross. ${ }^{8}$ If no binocular single vision in primary and reading position could be acquired (if need be with prisms up to 5 dioptres for each eye), further surgery was performed.

All patients with re-established binocular single vision were followed up at least one year postoperatively for recurrences.

'Optimal response' to surgery was defined as
Table I Synopsis of the muscles operated on in 38 patients with stable Graves'ophthalmopathy

Recession: inferior rectus Recession: medial rectus

Recession: contralateral superior rectus

Recession: inferiat

Recection: lateral reclique

Tenotomy: inferior + medial rectus 
Table 2 Results of extraocular eye muscle surgery in 38 patients with unchanging diplopia due to Graves' ophthalmopathy

\begin{tabular}{lrrcc}
\hline & $n$ & $\begin{array}{c}\text { Optimal } \\
\text { response }\end{array}$ & $\begin{array}{l}\text { Suboptimal } \\
\text { response }\end{array}$ & Failure* $^{\star}$ \\
\hline Hypotropia & 18 & 9 & 7 & 2 \\
Esotropia & 8 & 7 & 0 & 1 \\
Hypo-plus esotropia & 12 & 5 & 6 & 1 \\
Total & 38 & 21 & 13 & 4 \\
Percentage & 100 & 55 & 34 & 11 \\
\hline
\end{tabular}

^For definitions see text.

operation for single vision. 'Failures' were those in whom no single vision could be obtained or stronger prisms than 5 dioptres were required.

\section{Results}

Thirty-four (89\%) patients achieved binocular single vision in primary and reading positions (Table II). Twenty-seven patients needed one procedure, five needed two procedures, one patient three, and one four.

None of the patients became overcorrected in the primary position, but two out of 18 patients with preoperative hypotropia showed a limitation of depression postoperatively, requiring prisms in the reading position. One patient achieved single vision in both primary and reading position with a slight head tilt. Three other patients with hypotropia were undercorrected and needed weak prisms (up to 5 dioptres) for the residual angle.

In the group of patients with esotropia all but one regained single vision after one operation without the need for prisms. In the group of 12 patients with both hypo- and esotropia six fused after one operation and five after more than one. Four eventually needed weak prisms.

Comparing optimal responders and suboptimal responders plus failures, we found no differences in sex, age, duration of eye disease, angle of deviation, or prior forms of treatment between either group (Table III).

The results of surgery were not always obvious shortly after the operation. Some patients were still hypo- or esotropic during the first month after surgery, but became orthophoric within three months. On the other hand some patients were orthophoric shortly after surgery but

Table 3 Comparison between optimal responders and suboptimal responders plus failures

\begin{tabular}{|c|c|c|}
\hline & $\begin{array}{l}\text { Optimal } \\
\text { responders } \\
n=21\end{array}$ & $\begin{array}{l}\text { Suboptimal } \\
\text { responders } \\
\text { plus failures } \\
n=17\end{array}$ \\
\hline $\begin{array}{l}\text { Male/female } \\
\text { General/local anaesthesia } \\
\text { Age (years) } \\
\text { Surgeon 1/surgeon } 2 \\
\text { Duration GO median (range) } \\
\text { Prior treatment: }\end{array}$ & $\begin{array}{l}6 / 15 \\
13 / 8 \\
52 \cdot 6(10 \cdot 4) \\
6 / 15 \\
28(11-76 \mathrm{mo})\end{array}$ & $\begin{array}{l}5 / 12 \\
9 / 8 \\
56 \cdot 7(12 \cdot 3)^{\star} \\
6 / 11 \\
20 \cdot 5(8-48 \mathrm{mo}) \dagger\end{array}$ \\
\hline $\begin{array}{l}\text { no pretreatment } \\
\text { medical treatment only } \\
\text { radiotherapy } \\
\text { orbital decompression } \\
\text { Angle of deviation (dioptres) } \\
\text { (given for hypotropia only) }\end{array}$ & $\begin{array}{l}3 \\
4 \\
7 \\
7 \\
21(9 \cdot 6)\end{array}$ & $\begin{array}{l}1 \\
5 \ddagger \\
5 \ddagger \\
6 \neq \\
23(9 \cdot 4)^{\star}\end{array}$ \\
\hline
\end{tabular}

Notes: $\mathrm{GO}=$ Graves' ophthalmopathy. $\mathrm{mo}=$ Months. Data are expressed as the mean (with standard deviation) and were analysed by the two-sample, two-sided $t$ test ${ }^{\star}$; the median plus analysed by the two-sample, two-sided $t$ test ${ }^{\star}$; the median plus range and analysed using the Mann-Whitney $U$ test + ; real numbers. $\neq$ None of these differences appeared to be significant. developed a limitation of depression after one or two months. $74 \%$ of the patients stabilised within one month and the remaining $26 \%$ within three months. Long term follow-up showed no major alterations of the field of binocular single vision in any patient.

\section{Discussion}

Evans and Kennerdell reported a success in $88 \%$ of patients with Graves' ophthalmopathy after multiple procedures for diplopia, ${ }^{2}$ Dyer in $82 \%$ after one operation. ${ }^{6}$ Fells and McCarry, comparing fixed and adjustable sutures in patients with Graves' induced diplopia, obtained a long term success in $66 \%$ of patients operated on with fixed sutures and in $76 \%$ of patients with adjustable sutures. ${ }^{9}$ We prefer non-adjustable rather than adjustable sutures because the technique is simpler and only one intervention is necessary. Using fixed sutures, we obtained successful results in $71 \%$ after one and in $89 \%$ after more than one procedure.

Thus at least $11 \%$ of patients with Graves' ophthalmopathy do not respond well to surgery. As stated by Char, ${ }^{10}$ squint surgery in Graves' ophthalmopathy is not comparable to squint surgery in general. The extraocular muscles of patients with Graves' disease are taut and often bleed excessively. ${ }^{6}$ Eyelid swelling prevents easy access to the operative field. Because of the nature of the disease, postoperative scarring is considerable. These factors explain why binocular single vision without the use of prisms is not always obtained after one or even more surgical procedures.

We hypothesised that the preoperative duration of eye disease, the angle of deviation, or the prior treatment could influence these factors. Large angles of deviation demand more extensive surgery, and this in turn might influence the surgical outcome. Furthermore it has been thought that orbital irradiation produces more extensive fibrosis, which is a well known side effect of megavoltage radiation therapy, ${ }^{11}$ thus hampering extraocular muscle surgery. We could not detect any difference, however, in the above mentioned characteristics between the groups of optimal responders and the group of suboptimal responders plus failures. When patients pretreated with orbital irradiation were compared with those who were pretreated medically only, no difference was found between the two groups in surgical outcome. Nor was any significant difference found in relation to other types of prior treatment, duration of eye disease, or angle of deviation. These findings suggest that these characteristics have no predictive value for the outcome of surgery.

A possible cause of failure after extraocular muscle surgery for Graves' ophthalmopathy could be a relapse of the active inflammatory process. This seems highly unlikely in our patients, because features indicating activity of the disease, like changes of eyelid swelling, proptosis, and visual acuity, were absent. ${ }^{5}$ Failures in our series may be explained by the fact that we mainly recessed the extraocular muscles, and recessions displace the centre of rotation of the eyeball, thus influencing the 
surgical result. This might be prevented by doing a recession together with a resection of the antagonist, as advised by Crone. ${ }^{8}$ In this series we performed an additional resection of the lateral rectus in three patients with very tight muscles, resulting in an optimal response in two of them.

In one patient the angle of deviation did not change after the involved muscle had been completely detached from the globe. Even by pulling the eyeball into the primary position the deviation could not be changed. This can only be explained by extensive fibrosis of the orbital connective tissue system. ${ }^{12}$ Recurrences of diplopia were not found during a follow-up period of one year, most certainly because most patients were constantly euthyroid prior to surgery, and no patient was operated on before all signs of disease activity ${ }^{5}$ had disappeared completely.

In conclusion, this study shows that long term satisfactory results of extraocular muscle surgery in patients with stable Graves' ophthalmopathy can be achieved in almost $90 \%$ of the cases without the need for adjustable sutures. The outcome of surgery is not influenced by the duration of the disease, the preoperative angle of deviation, sex or age, or by the sort of preoperative treatment.

1 Wiersinga WM, Smit T, van der Gaag R, Mounts $M$, Koornneef $L$. Clinical presentation of Graves' ophthalmopathy. Ophthalmic Res 1989; 21: 73-82.

2 Evans D, Kennerdell JS. Extraocular muscle surgery for dysthyroid myopathy. Am $\mathcal{F}$ Ophthalmol 1983; 95: 767-71.

3 Wiersinga WM, Smit T, Schuster-Uittenhoeve ALJ, van der Gaag R, Koornneef L. Therapeutic outcome of prednisone medication and of orbital irradiation in patients with Graves' ophthalmopathy. Ophthalmologica 1988; 197: 75-84.

4 Hurbli T, Char DH, Haris J, Weaver K, Greenspan F, Shelline G. Radiation therapy for thyroid eye disease. $\mathbf{A m}$ f Ophthalmol 1985; 99: 633-7.

5 Mourits MPh, Koornneef L, Wiersinga WM, Prummel MF, Berghout A, van der Gaag $R$. Clinical criteria for the assessment of disease activity in Graves' ophthalmopathy: a novel approach. Brf Ophthalmol 1989; 73: 639-44.

6 Dyer JA. Ocular muscle surgery. In: Gorman CA, Waller RR, Dyer JA, eds. The eye and orbit in thyroid disease. New York: Raven Press, 1984.

7 Werner SC. Classification of the eye changes of Graves' disease. F Clin Endocrinol Metab 1969; 29: 982-4.

8 Crone RA. Motility disturbances in cases of endocrine exophthalmos. In: Crone RA, ed. Diplopia. Amsterdam: Excerpta Medica, 1973: 350-60.

9 Fells P, McCany B. 'Fixed' versus 'adjustable' sutures in the treatment of dysthyroid ophthalmopathy. In: Murube I, ed. Acta XVII Concilii Europaeae Strabologicae Associetatis. Acta XVII Concilii Eurc

Madrid: 1988: $239-42$.
10 Char DH. Therapy of thyroid myopathy. In: Gardner JN, ed. Thyroid eye disease. Baltimore: Williams and Wilkins, 1985.

11 Fletcher GH. Clinical parameters. Textbook of radiotherapy. Philadelphia: Lea and Febiger, 1973: 133.

12 Koornneef $L$. Eyelid and orbital fascial attachments and their clinical significance. Eye 1988; 2: 130-4. 